\title{
PERCEPÇÕES DOS MEMBROS DE UMA INSTITUIÇÃO DE ENSINO A RESPEITO DAS CONCEPÇÕES PEDAGÓGICAS
}

\section{Perceptions of members of a teaching unit about pedagogical conceptions}

\author{
Tiago Ravel Schroeder (tiagoravel13@gmail.com) \\ Instituto Federal Catarinense - campus Ibirama (IFC) \\ Indianara Cucco (indicucco@gmail.com) \\ Escola de Ensino Fundamental Bernardo Rohden (EEFBR) \\ Morgana Scheller (morganascheller@yahoo.com.br) \\ Instituto Federal Catarinense - campus Rio do Sul (IFC)
}

Resumo: O trabalho apresenta reflexões decorrentes do Estágio Supervisionado Curricular Obrigatório III de um curso de Licenciatura em Matemática. Objetiva compreender como os diversos envolvidos no cotidiano escolar de uma Instituição de Ensino percebem os conceitos de Escola, Educação, Sociedade, Homem e Avaliação, concepções pedagógicas da mesma. Os dados foram constituídos mediante documento institucional e entrevistas estruturadas realizadas com a gestão da Instituição, setor pedagógico, docentes e discentes. Utilizou-se de triangulação de métodos e dados e a análise aponta para a existência de diversas tipos de uma mesma concepção e também de diversidade delas entre os envolvidos, exceto na concepção de Escola. Destaca-se que apenas as concepções de Educação e Escola se aproximam do explicitado no Projeto Político Pedagógico (PPP). Tais considerações indicam que deve se investir em formação, encontros para estudo e outras investigações na Instituição envolvendo seus membros para que a convergência dessas se manifeste não apenas no PPP, uma vez que elas são referência para o trabalho a ser desenvolvido na Instituição. Concluiu-se que a atividade contribuiu para a formação profissional dos acadêmicos uma vez que considerou a instituição de ensino como objeto de análise, de investigação e de interpretação crítica, em um exercício de pesquisa no estágio.

Palavras-chave: Formação de professores; Escola; Estágio de Observação.

Abstract: The paper presents reflections arising from the Compulsory Curricular Supervised Internship III of a Mathematics Degree course. It aims to understand how the diverse involved in the daily life of a teaching unit perceive the concepts of School, Education, Society, Man and Evaluation, pedagogical conceptions of the same. The data were constituted by institutional document and structured interviews conducted with the management of the School Unit, pedagogical sector, teachers and students. We used triangulation of methods and data and the analysis points to the existence of several types of the same conception and also their diversity among those involved, except in the conception of School. It is noteworthy that only the conceptions of Education and Education are close to the explicit in the Pedagogical Political Project (PPP). These considerations indicate that it is necessary to invest in training, study meetings and other 
investigations in the Institution involving its members so that their convergence manifests not only in the PPP, since they are a reference for the work to be developed in the Institution. It was concluded that the activity contributed to the professional formation of academics since it considered the educational institution as an object of analysis, investigation and critical interpretation, in a research exercise in the internship.

Keywords: Teacher training; School; Observation Stage.

\section{INTRODUÇÃO}

No decurso da formação inicial de um curso de Licenciatura em Matemática os acadêmicos necessitam aproximar-se do espaço escolar e o Estágio Supervisionado Curricular Obrigatório é uma das oportunidades. Entendendo o Estágio Curricular como um campo de conhecimento, este possui a finalidade de "integrar o processo de formação do aluno, futuro profissional, de modo a considerar o campo de atuação como objeto de análise, de investigação e de interpretação crítica" (PIMENTA; LIMA, 2012, p. 24).

Uma das primeiras ações relativas ao Estágio Curricular diz respeito às observações no referido campo. Serve também para o acadêmico ter noção de que sua futura ação docente em sala de aula não é isolada, tendo relação e interferências de vários aspectos, infraestrutura e profissionais envolvidos no cotidiano escolar. Dentre eles destacamos o espaço escolar, o coordenador pedagógico, a secretaria, o professor de apoio, às concepções eleitas e expressas no Projeto Político Pedagógico (PPP), entre outros. É importante ao estagiário inteirar-se desse movimento para entender melhor sua contribuição no espaço escolar de modo a garantir a função social da Escola, quando vier atuar. Carvalho (2012, p. 11) expressa que o estágio de observação deve proporcionar aos "futuros professores condições para detectar e superar uma visão simplista dos problemas de ensino e aprendizagem, proporcionando dados significativos do cotidiano escolar que possibilitem uma reflexão crítica" do trabalho a ser desenvolvido nesse espaço, bem como a estrutura que existe para isso.

Assim, no estágio de observação tem-se a possibilidade da formação de um professor reflexivo que realiza releituras da realidade escolar, entendendo-a no sentido plural. E esse processo é denso pois “observar uma situação pedagógica é olhá-la, fitála, mirá-la, admirá-la, para ser iluminado por ela" (FREIRE, 1992, p. 14). Portanto, a observação conduz a uma percepção mais aprofundada acerca das complexidades 
existentes no cotidiano escolar, sendo imprescindível a existência de reflexão acerca dos principais entes do objeto analisado.

Uma das ações durante a observação é inteirar-se do teor existente no Projeto Político Pedagógico (PPP), uma vez que ali deve estar expresso as intenções da Escola, suas metas e objetivos, dentre outros. No documento, que expressa a identidade da Escola, deve estar materializada as representações dos pensamentos da comunidade escolar, já que deve ser resultado de um compromisso sociopolítico definido coletivamente (VEIGA, 2004). No entanto, na prática, supõe-se que as concepções registradas nem sempre representam um eixo norteador para a comunidade escolar como deveriam. Assim, na perspectiva de fazer uso da pesquisa no Estágio e o Estágio como pesquisa na compreensão de Pimenta e Lima (2012), origina-se este trabalho que deriva do relatório do Estágio de Observação de dois acadêmicos de um curso de Licenciatura em Matemática, realizado no primeiro semestre de 2018.

Embora os acadêmicos já tivessem realizado uma parte do Estágio na mesma Instituição, questões que não ficaram bem esclarecidas na etapa anterior foram retomadas, dentre elas, as percepções dos vários envolvidos na comunidade escolar acerca das principais concepções pedagógicas. Parte-se do pressuposto que, para melhor alcance dos objetivos expressos no PPP, os quais são discutidos pelo coletivo da Instituição no início de cada ano escolar, todos os membros da comunidade escolar deveriam pautar seu trabalho em concepções traçadas no plano coletivo. Sendo assim, procura-se por respostas para a pergunta: Como diferentes envolvidos no cotidiano de uma Escola compreendem suas concepções pedagógicas?

Para tanto, o texto que segue apresenta inicialmente considerações teóricas a respeito de algumas das concepções pedagógicas. Em seguida, delineia os procedimentos da pesquisa, apresenta e discute os dados coletados e por fim, são apresentadas algumas considerações.

\section{ARTICULAÇÕES TEÓRICAS ENTRE AS CONCEPÇÕES PEDAGÓGICAS}

Com intuito de analisar as concepções da Instituição de Ensino convém explicitar o que academicamente se discute a respeito desses conceitos. Assim, nesta seção 
apresenta-se definição para cada um dos cinco conceitos analisados no artigo, a saber:

Educação, Escola, Homem, Sociedade e Avaliação.

A respeito da Educação, Saviani (1984) defende que a mesma está imbricada ao trabalho. Isso se deve ao fato de que para esse autor, o trabalho é uma ação intencional. Mais do que isso, ela é o que diferencia o ser humano dos animais, pois para os Homens, o processo de produção da existência humana implica, primeiramente, na garantia da sua subsistência material com a consequente produção, em escalas cada vez mais amplas e complexas, de bens materiais. Já para os animais, basta o instinto de sobrevivência para sua subsistência individual, não havendo necessidade de acumulação como resultado de suas ações.

Nesse sentido, Saviani $(1994,2007)$ salienta que houve três momentos históricos na relação entre Educação e trabalho que nortearam as concepções de Educação: o comunismo primitivo, a Grécia antiga e a revolução industrial. O primeiro momento, delineou-se com a configuração de que apenas havia Educação no âmbito do trabalho, isso porque as relações sociais existentes bastavam-se na progressão do ofício desenvolvido para as gerações futuras.

No momento seguinte, a Educação foi a condição que afastava o sujeito do trabalho. As relações sociais vigentes no período segregavam os indivíduos que trabalhavam daqueles que se educavam. Aprender a profissão nesse período diz respeito a reprodução. $\mathrm{O}$ sentido educacional ficou restrito à Escola, constituída como lugar do ócio para os filhos de quem detinha o poder, aqueles que não precisavam trabalhar. Sua função na sociedade era comandar e deste modo não lhes caberia aprender qualquer profissão que envolvesse trabalhos manuais.

Já o terceiro momento, proporcionou a "universalização" da Educação no âmbito escolar, mas diferenciando as formas de difusão do conhecimento de acordo com a função que o sujeito desenvolveria no mercado de trabalho. Para Saviani (1994, 2007), essa última concepção de Educação é mais aceita, pois é a que divide os momentos de educação e de trabalho, uma vez que ela é dada exclusivamente no ambiente escolar.

Devido aos fatores apresentados é possível considerar que a Educação atualmente é elitizada, mas distinta do modelo grego. A elitização diz respeito aos objetivos dela para diferentes públicos. Com efeito, Saviani $(1994,2007)$ defende que existem formas de Educação diferente para os extratos (classes) da sociedade. Essa diferença está no 
trabalho que se espera que cada indivíduo desenvolva no futuro. Isso porque, segundo o autor, a Educação propedêutica é destinada às elites, ao passo que a instrucionista, à classe trabalhadora.

Um desdobramento dessa concepção é visto em Bueno e Pereira (2013) quando entendem que a Escola enfrenta inúmeros desafios oriundos do modo que foi conduzida a construção histórica dessa instituição, modo esse que não permitiu superar a referida elitização. Nesse sentido, um desafio dessa instituição "está na universalização de um ensino básico de qualidade: que prepare para o trabalho, para cidadania, cuidando da formação da personalidade nos aspectos afetivos e éticos" (ARANHA, 1996, p. 73).

Com efeito, é possível entender o conceito de Escola atual, local onde acontece a difusão do conhecimento científico selecionado para determinado público, categorizado por faixa etária, condição econômica e projeção de carreira. Para Saviani (1987, p. 14), a Escola "é uma instituição cujo papel consiste na socialização do saber sistematizado". Ela deve possibilitar a aquisição de conteúdos - de modo que o educando tenha discernimento e conhecimento para analisar a realidade de modo crítico -, bem como a socialização do educando para que o mesmo tenha uma participação organizada na democratização da Sociedade.

Esses modelos de Educação e de Escola, estratificam a Sociedade e fazem o conhecimento científico ser parcializado e chegar às diversas classes econômicas de weber forma diferente. Por exemplo, a classe média convive com uma Sociedade da informação, entendida como aquela em que "o importante [...] não é a tecnologia em si, mas as possibilidades de interação que elas proporcionam através de uma cultura digital" (COUTINHO; LISBOA, 2011, p. 8). Por outro lado, a classe alta tem acesso a universalização desse conhecimento, "entendido como a capacidade [...], diante da informação, de desenvolver uma competência reflexiva, relacionando os seus múltiplos aspectos" (COUTINHO; LISBOA, 2011, p. 9). Isto conduz esse extrato social para uma Sociedade do conhecimento.

De acordo com Rodrigues (2007), o conceito de Sociedade apresenta distintas concepções. Karl Marx ${ }^{1}$ (1818-1883), entende que o processo histórico da luta de classes, da mesma maneira como trouxe o capitalismo, deveria extingui-lo. Nesse sentido, a Educação, que serviu de ideologia para mascarar a reprodução das relações de

\footnotetext{
${ }^{1}$ Sociólogo alemão que defende que a Sociedade tem classes sociais que apenas se perpetuam pela falta do senso coletivo.
} 
classe no capitalismo, deve emancipar o Homem preparando-o para viver na Sociedade comunista.

Em contexto semelhante, Émile Durkheim² (1858-1917) considera que os fatos sociais influenciam os indivíduos, assim como os esses determinam o tipo de Sociedade que vivem. Conforme a ênfase dada a cada uma dessas possibilidades há maior ou menor consenso social, podendo ser ela homogênea ou heterogênea. Já para Weber ${ }^{3}$ (1864-1917), a relação entre Sociedade e Educação se estabelece com as interações entre indivíduos, racionalmente baseadas em valores. Nessa perspectiva, o autor concebe a Sociedade como uma teia e nela, a Educação teria a função de racionalizar e treinar os membros para a busca de capital e poder (RODRIGUES, 2007).

Nesse sentido, é possível perceber ainda diferenças nos indivíduos que compõem uma Sociedade, ou seja, são diferentes as concepções de Homem. Essa adaptação do indivíduo ao meio é defendida pela teoria histórico-cultural de Vygotsky (1987, p. 3) ao afirmar que "a verdadeira trajetória [...] não vai no sentido do pensamento individual para o socializado, mas do pensamento socializado para o individual". Assim, pode-se dizer que Homem é todo membro de uma Sociedade, variando os tipos de acordo com a Sociedade em que este convive.

Os conceitos apresentados anteriormente se articulam em uma Unidade de Ensino por meio do modo com que são mensurados, pois "a avaliação no contexto escolar realiza-se segundo objetivos escolares implícitos ou explícitos, que, por sua vez, refletem valores e normas sociais" (CHUEIRI, 2008, p. 3). Este modo reflete o modelo da Proposta Curricular de Santa Catarina (PCSC) onde

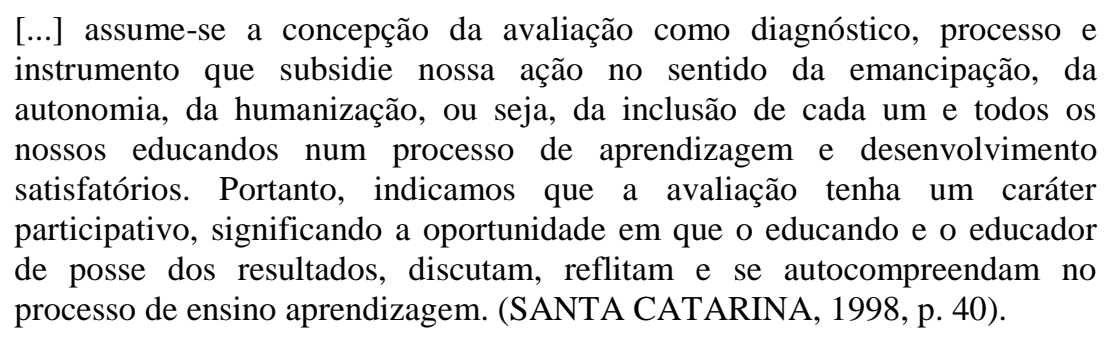

Há diversas possibilidades para isso, uma delas é entender que avaliar "é o ato de diagnosticar uma experiência, tendo em vista orientá-la para produzir o melhor

\footnotetext{
${ }^{2}$ Sociólogo francês que acredita que a Sociedade rege as relações entre os indivíduos por meio da coesão social.

${ }^{3}$ Sociólogo alemão, na sua visão a sociologia é explicada pelas ações dos indivíduos, que moldam a Sociedade por meio de ações sociais.
} 
resultado possível” (LUCKESI, 2002, p. 5). Nesse, caso centra-se nas práticas pedagógicas de sala de aula. Por outro lado, o "ato de avaliar incide sempre sobre alguma coisa que existe” (p. 7). Nesse cenário, agregam-se práticas extraclasse, tendo em vista o papel social da Instituição de Ensino no contexto que está inserida.

Outra possibilidade é entender que a "prática de avaliação dos processos de ensino e de aprendizagem ocorre por meio da relação pedagógica que envolve intencionalidades, [subjetividades] [..], atitudes e habilidades dos atores envolvidos" (CHUEIRI, 2008, p. 4, inserção nossa). Assim, percebe-se que a mesma possibilita considerar o máximo de aspectos intrínsecos referentes aos estudantes. Afinal, defende que "para além da investigação e da interpretação da situação, a avaliação envolve necessariamente uma ação que promova a sua melhoria" (HOFFMANN, 2009, p. 17).

Conscientes do referencial teórico apresentado nessa seção, foram organizados os procedimentos metodológicos para a coleta e análise de dados que caracterizassem esses conceitos por meio da visão de diferentes membros da comunidade escolar da Instituição observada. Tais procedimentos são destacados na sequência.

\section{ASPECTOS METODOLÓGICOS}

O estudo objetiva analisar e descrever como os diferentes participantes de uma comunidade compreendem as concepções pedagógicas (Escola, Educação, Sociedade, Homem e Avaliação) que norteiam o trabalho escolar. O estudo deriva de um estudo maior realizado no primeiro semestre de 2018 por dois dos autores deste artigo e orientado pelo terceiro, no âmbito do Estágio Supervisionado Curricular Obrigatório III do curso de Licenciatura em Matemática de uma instituição pública do sul do Brasil, durante o período de observação.

Em termos metodológicos o estudo segue abordagem qualitativa e interpretativa (ALVES-MAZZOTTI, 1998; BOGDAN; BIKLEN, 1994) pois busca compreender detalhadamente os significados atribuídos pelos participantes da pesquisa às suas vivências e conhecimentos num contexto escolar. Ademais apresenta as características de investigação qualitativa descritas por Bogdan e Biklen (1994). Trata-se de um estudo de caso, ou seja, "observação detalhada de um contexto, ou indivíduo, de uma única fonte de documentos ou de um acontecimento específico" (p. 89.) 
Os dados, constituídos mediante consentimento livre e esclarecido, constam de documento institucional (KRIPKA; SCHELLER; BONOTTO, 2015) denominado Projeto Político Pedagógico (PPP) e entrevistas estruturadas realizadas com a gestão da Instituição de Ensino (IE) na figura do diretor (D), o setor pedagógico representado pela orientadora educacional (OE) e pela supervisora educacional (SE), o professor supervisor (PS), a segunda professora da turma (SP) e pelos 22 estudantes (E) do segundo ano V do Ensino Médio. Utilizou-se de codificação para diferenciar os diferentes sujeitos, bem como preservar o anonimato dos sujeitos da pesquisa. A entrevista pauta-se em questões relacionadas à Escola, Educação, Sociedade, Homem e Avaliação, objetivando "compreender, com bastante detalhe, o que é que professores, diretores e estudantes pensam e como é que desenvolveram os seus quadros de referência" (BOGDAN; BIKLEN, 1994, p. 17).

O estudo do PPP é realizado de acordo com a compreensão de Flick (2009), que entende o documento como um meio de comunicação, elaborado com um propósito e tendo alguma finalidade, sendo inclusive destinado para acesso de outras pessoas. Assim, o PPP pode ser entendido como uma forma de contextualização da informação, sendo analisado como "dispositivo comunicativo metodologicamente desenvolvido na produção de versões sobre eventos" (p. 234). Já as entrevistas, utilizadas para complementação dos dados, foram utilizadas para "recolher dados descritivos na linguagem do próprio sujeito, permitindo ao investigador desenvolver intuitivamente uma ideia sobre a maneira como os sujeitos interpretam aspectos" das concepções pedagógicos em seu contexto escolar (BOGDAN; BIKLEN, 1994, p. 134). Destaca-se que os dados obtidos nas entrevistas foram transcritos para facilitar o processo de análise.

Para a análise e interpretação dos dados utiliza-se da perspectiva da triangulação de coleta de dados e métodos de Denzin (1978) e Zanelli (2002). Afinal, ela é "uma alternativa à validação. A combinação de diferentes perspectivas metodológicas, diversos materiais empíricos [...] num só estudo devem ser vista como uma estratégia para acrescentar rigor, amplitude, complexidade, riqueza e profundidade" em qualquer investigação (DENZIN; LINCOLN, 2000, p. 36, tradução nossa). Tal perspectiva pressupõe olhar para as concepções pedagógicas que permeiam a UE, a partir dos dados obtidos nas entrevistas, os oriundos do documento norteador da UE - PPP, bem como 
pressupostos teóricos relacionados a cada tema. Daí então emerge a compreensão dos autores. Assim, a análise permite

[...] verificar se o conteúdo de uma verbalização tem correspondência com uma fonte documental. Posteriormente, a análise é feita com o olhar em alternância para os dados, para os conceitos ou teorias que a literatura apresenta sobre aqueles assuntos e para a articulação que o pesquisador percebe como lógica na construção discursiva (ZANELLI, 2002, p. 86).

Assim, seguindo tal procedimento, apresenta-se a seguir os resultados e discussão do estudo.

\section{RESULTADOS E DISCUSSÃO}

A análise permitiu a explicitação e compreensão das significações das concepções pedagógicas que os envolvidos na comunidade escolar atribuem em seu cotidiano escolar. Do processo emergiram diferentes concepções, ilustradas no Quadro 1 que, em seguida serão descritas e discutidas as significações, fundamentando-as na teoria e ancoradas nos protocolos dos sujeitos e nos preceitos presentes no PPP.

Quadro 1 - Síntese das percepções dos membros da comunidade escolar acerca das concepções.

\begin{tabular}{|c|l|}
\hline Concepção & \multicolumn{1}{c|}{ Percepções } \\
\hline \multirow{2}{*}{ Escola } & Difusão do conhecimento \\
\cline { 2 - 2 } Educação & União entre ciência e empirismo \\
\cline { 2 - 2 } & Sentido moral ou técnico \\
\cline { 2 - 2 } & Função social \\
\cline { 2 - 2 } Sociedade & Social \\
\hline \multirow{2}{*}{ Homem } & Conjuntos de indivíduos \\
\cline { 2 - 2 } & Sociologia de Durkheim \\
\cline { 2 - 2 } & Sociologia de Marx \\
\cline { 2 - 2 } & Auto identificação \\
\hline \multirow{2}{*}{ Avaliação } & Escolar \\
\cline { 2 - 2 } & Liberal \\
\cline { 2 - 2 } & Social \\
\hline
\end{tabular}

Fonte: Elaborado pelos autores (2019).

A respeito da concepção de Escola, cerca de $80 \%$ estudantes da turma concebemna como o local de difusão do conhecimento. Para eles, "é um lugar onde vou para estudar, para ampliar os meus conhecimentos" (E4), conceito que vai ao encontro do 
estabelecido por Saviani (1987) quando expressa que a Escola é valorizada como instrumento de apropriação do saber, lugar de socialização do saber sistematizado, mas “[...] não se trata, pois, de qualquer tipo de saber. [...], a escola diz respeito ao conhecimento elaborado e não ao conhecimento espontâneo; ao saber sistematizado e não ao saber fragmentado; à cultura erudita e não à cultura popular" (SAVIANI, 1984, p. 2). Porém, os estudantes não especificam se estavam referindo-se ao conhecimento usado para fazer Ciência (científico) ou aquele necessário para o convívio social (empírico).

Outros depoentes ainda congregam as duas facetas do papel escolar, entendendo a Escola como difusora do conhecimento científico e empírico. Desse modo estão de acordo com a concepção do PPP da UE, ao considerar que "o papel maior da Escola é o de ajudar o cidadão a se instrumentalizar efetivamente para a tomada de decisões de seu próprio destino e, consequentemente, do destino da Sociedade” (EEBRM, 2018, p. 127). Assim como para o professor, a equipe gestora e também para esses estudantes, a "escola é uma instituição que forma novos profissionais, que educa e prepara um cidadão para a Sociedade através do conhecimento" (E1) e "é a instituição que frequentamos para nos tornar seres humanos melhores e capazes" (E19). Embora tais fragmentos contemplem o que esses sujeitos vivenciam cotidianamente, os protocolos aproximam-se da definição amplamente encontrada em dicionários. A saber: Escola como uma "Instituição pública ou privada que tem por finalidade ministrar ensino coletivo" (MICHAELIS, 2019).

Em relação à concepção de Educação, identificou-se que a mesma é heterogênea entre os diferentes participantes dessa comunidade escolar. Nesse sentido, a maior parcela dos estudantes concebe o termo, não no sentido escolar, mas no sentido moral ou técnico. Identifica-se isso quando os mesmos afirmam que "Educação seria aquilo que aprendemos em casa" (E3), opinião esta também compartilhada pelo professor de matemática (PS) e que atende ao que Saviani (1984) considera uma parte da Educação, o conjunto de saberes historicamente acumulados que contribuem para a formação propedêutica. Outros, no sentido preparatório para o mundo do trabalho, concebem a Educação como "algo fundamental para um futuro melhor" (E12), que evidencia outra faceta da concepção de Educação de Saviani (1984), o saber científico, que está ligado a profissão e ao trabalho futuramente desenvolvido. Ainda outros mesclam as 
responsabilidades dessa Educação moral, ao afirmarem que “Educação vem da família e da escola" (E4).

Oito estudantes entenderam a função social da Educação escolar, ao perceberem que ela "é um complemento para fornecer inteligência ao homem, o qual vive em sociedade e passa por diversas avaliações durante sua vida para testar seus conhecimentos" (E9), o que se aproxima da concepção expressa no PPP: "Educação [...] tem por finalidade o pleno desenvolvimento do educando, seu preparo para o exercício da cidadania e sua qualificação para o trabalho" (EEBRM, 2018, p. 101). Coadunando com isso, E5 e E10 expressam, respectivamente, que a Educação "é minha forma de crescimento em mentalidade e em vida", "é o ato ou aprendizado que uma pessoa tem e passa adiante, eticamente, psicologicamente ou educacionalmente". Tais percepções podem ser sintetizadas pela concepção da OE, que entende que a Educação pode ser definida como sendo o processo de socialização dos indivíduos. Para ela, ao receber Educação, a pessoa assimila e adquire conhecimentos. "A Educação também envolve uma sensibilização cultural e de comportamento, onde as novas gerações adquirem as formas de se estar na vida das gerações anteriores" (OE).

Um dos principais obstáculos presentes na Educação é a falta de materiais adequados, estrutura e reconhecimento, o que é destacado pela SE quando cita que "toda a teoria já é bem conhecida [...] busca-se qualidades, mas faz-se necessário mais investimento, comprometimento $"$ para que a Educação seja de qualidade. Coadunando a isso, destaca-se o aporte de PS que a vê "como salvação de muitos povos, mas que aqui não é visto com bons olhos, se fosse, teria mais incentivo e cobrança”.

Ressalta-se que esta concepção heterogênea de Educação necessita ser bem gerenciada, pois, se assim for, o processo educacional ganha em pluralidade de objetivos, o que faz a Educação atender várias das visões destacadas. Entretanto, caso isso não aconteça, o processo educacional pode divergir para atingir as concepções individuais, já que Educação pode ser entendida, apenas como um "conjunto de métodos próprios a fim de assegurar a instrução e a formação do indivíduo" (MICHAELIS, 2019). Neste sentido, entende-se que a coesão entre as percepções dos indivíduos e do PPP é fundamental para o funcionamento exitoso da UE.

No que tange o conceito de Sociedade, quinze (15) estudantes a compreendem como o conjunto de indivíduos que se relacionam e mostraram ter consciência de que estão inseridos nela, pois a "Sociedade é uma comunidade que todo mundo se ajuda" 
(E6). Esta visão coincide com a do professor de matemática, que também acrescenta ser função da Escola "formar cidadãos críticos, pensantes, inovadores" (PS). Esse é um conceito de Sociedade que remete ao senso comum, mas ainda assim é importante no ambiente educacional por referir-se ao "Agrupamento de pessoas que vivem [...] em cooperação mútua" (MICHAELIS, 2019) e oportuniza a construção da ideia de conjunto, alicerce importante para discussões aprofundadas sobre Sociedade e sociologia.

Noutra perspectiva, duas respostas remeteram-se à sociologia clássica, em que as relações sociais têm motivo e objetivo, "uma forma de produção social que estão organizadas e engloba força, produção e a realização" (E4). A resposta, mesmo que superficial, remete à sociologia de Émile Durkheim. E19, por sua vez promoveu reflexões sobre a desigualdade social, ciente de que Sociedade é um conjunto de relações. O estudante acredita que "Sociedade não deveria ser tão individualista, o indivíduo é a principal fonte, pessoas divididas em classes sociais" (E19), o que remete a outro sociólogo clássico, Karl Marx.

Em referência ao conceito de Homem, em sua maioria, os protocolos dos estudantes e do professor de matemática (SP) convergem para o entendimento de que este é um "ser racional seguido de valores" (E12) e eles próprios se veem nessa condição ao afirmarem que "somos todos nós, homens e mulheres" (E3). Ambos fragmentos corroboram a visão de Vygotsky (2001), afinal o Homem é parte da sociedade. Para ele, o indivíduo é aquele sujeito composto por uma série de valores que contêm um conjunto de conhecimentos próprios de história e cultura.

Associando ao conceito anterior, escreveram ainda que o Homem "é o que compõe a Sociedade" (E6). Este conceito é um reflexo da ideia de conjunto que emergiu no conceito anterior de Sociedade e, do mesmo modo, coincide com a definição Michaelis (2019), que diz respeito “A espécie humana”. Aqui se pode perceber o sentido de humanidade.

Atentando-se às possíveis funções do Homem, quatro estudantes analisaram o papel social, mas ainda ressaltando o caráter racional de sua atuação ao expressarem que "Homem é alguém que lida com dificuldades, problemas, decisões, de forma como tal e age sendo um, com respeito e ética, não agindo como animal e não sendo egoísta" (E10). O que se aproxima da definição da OE, quando expressa que "o Homem é um ser destinado ao saber, pois é o único animal que pensa, raciocina e tem noção que está 
incluído no mundo" (OE). Tais concepções mostram-se mais aprofundadas que as anteriores desse mesmo conceito, justamente por considerarem a individualidade com um papel social.

Ainda se tratando de possíveis funções do Homem, duas respostas criticaram o preconceito praticado: “[...] racista muitas vezes [...]" (E17) e "em muitos casos ainda existem homens que [...] são extremamente machistas" (E19). Estes excertos evidenciam que o preconceito é presente também na UE e sua discussão e combate devem ser oportunizados durante as aulas.

No que diz respeito à Avaliação, a maioria dos estudantes discorreu referindo-se ao sentido escolar do termo, e não no geral. Segundo E10, "é um teste que comprova que tal pessoa tem conhecimento, domínio sobre certo conteúdo, se conseguir fazê-lo corretamente". Outros ainda possuem uma visão neoliberal ${ }^{4}$ sobre o tema ao considerarem que Avaliação é "a nota, referente ao mérito" (E21), o que coincide com a definição geral de Avaliação em Michaelis (2019): "Apreciação, cômputo ou estimação da qualidade de algo ou da competência de alguém". Esta concepção contraria a da OE quando considera que "Avaliação não deve ser somente no momento da realização das provas e testes, mas um processo contínuo e que ocorre dia após dia, visando a correção de erros e encaminhando o aluno para aquisição dos objetivos". Tal concepção converge para o exposto no PPP, que contempla que "a Avaliação [...] será contínua e de forma global, mediante verificação de competência e de aprendizagem de conhecimentos" (EEBRM, 2018, p. 19). A orientadora ainda acrescentou que "a Avaliação é um processo formativo que compreende pelo menos três etapas inter-relacionadas: diagnóstico, intervenção e replanejamento" (OE). Destacase que as concepções até aqui trazidas são contraditórias, sendo entendida no sentido pontual (produto) pelos estudantes e formativa (processo) pela OE.

Por outro lado, atentos ao papel social da Avaliação, alguns estudantes associaram o conceito às dificuldades do dia a dia, quando "somos colocados em provas todo o momento, enfrentamos e superamos várias coisas" (E19). Tal conceito extrapola a caixinha da nota e da Avaliação escolar, transformando-a em uma ação social, um conceito da sociologia weberiana.

\footnotetext{
${ }^{4}$ Corrente filosófica que defende o neoliberalismo. Nesta corrente o mercado é visto como regulador das relações sociais e as maiores e melhores oportunidades estão à disposição do capital.
} 
A diversidade encontrada no conceito não é surpreendente, apenas um reflexo do conceito de Educação, pois como percebeu-se diversas concepções do que é ou do que esperar sobre Educação, é natural que o conceito de Avaliação esteja relacionado ao modo de acompanhar, ao modo de se chegar aos objetivos educacionais, também sejam diversos. Porém, por tratar-se de um contexto escolar, defende-se que a Avaliação deva ser contínua e processual visto que ela "é o ato de diagnosticar uma experiência, tendo em vista orientá-la para produzir o melhor resultado possível” (LUCKESI, 2002, p. 5). Ademais, este processo deve ser qualitativo, pois deve "estar atento ao aperfeiçoamento, ao aprofundamento da aprendizagem, seja no campo afetivo, seja no cognitivo, ou no psicomotor" (p. 10).

Entre as concepções dos estudantes a respeito de Avaliação, identificou-se uma expressão que congrega boa parte dos conceitos discutidos à respeito das concepções pedagógicas da Escola: "entendo que o Homem na sociedade é constantemente avaliado por todas as suas ações. A função da Educação é prepará-lo para isso" (E1). Tal expressão reafirma o potencial de criticidade e discussão da turma, que foi percebido desde as observações das aulas de matemática. Sendo assim, esses estudantes concebem a como parte da atividade humana de reflexão, portanto, é intencional e aplicável a qualquer prática e em diversas atividades, pois "uma avaliação reflexiva auxilia a transformação da realidade avaliada" (HOFFMANN, 2009, p. 10).

\section{CONSIDERAÇÕES FINAIS}

Buscar compreender como os diferentes participantes de uma comunidade compreendem algumas das concepções pedagógicas que norteiam o trabalho escolar foi o propósito deste estudo. A análise realizada a respeito das concepções, possibilita inferir que em relação à concepção Escola, os sujeitos a compreendem como lugar de difusão de conhecimento e união entre ciência e empirismo. Já o conceito de Educação foi citado com sentido moral ou técnico e com sua função social. Por sua vez, o conceito de Sociedade emergiu mediante três principais visões: (i) como conjunto de indivíduos; (ii) na perspectiva sociológica de Durkheim e também (iii) revisitando conceitos marxistas. No que concerne a concepção de Homem, houve apresentação no sentido de auto identificação e com o papel social visando a atuação racional. Por fim, o conceito de Avaliação foi contemplado nos sentidos: escolar, liberal e social. Sinteticamente expressa essa síntese no Quadro 1. 
Em relação às concepções de Escola, Educação, Sociedade, Homem e Avaliação, percebeu-se que existe heterogeneidade por parte dos envolvidos, exceto no quesito Escola. Então, cada sujeito, de acordo com sua função dentro da comunidade escolar ocupa um posicionamento. No entanto, tais posicionamentos produzem resultados ambíguos, que ora esses podem ser benéficos quando aumentam a pluralidade de ideias como no caso de uma discussão, ora são maléficos como no caso de criar desacordos que não contribuem para um caminhar objetivo da comunidade escolar.

Constatou-se que as concepções de Educação e de Escola se aproximaram do explicitado no PPP e, os demais conceitos, por serem pouco explorados, tanto no texto do documento como em discussões presenciais, divergiram de acordo com as experiências de cada sujeito. Tais constatações feitas em contexto de formação inicial julgam-se importantes por proporcionar conhecimentos para os acadêmicos e formadores acerca dos bastidores da comunidade escolar, o que corrobora a formação dos primeiros e consolida o estágio como espaço para pesquisa.

Em relação às implicações, sugere-se que Instituição proponha e propicie discussões mais aprofundadas e articuladas com os membros da comunidade escolar de modo a possibilitar a reconfiguração das concepções desses, com foco no alinhamento aos preceitos teóricos que embasam tais concepções. A partir das compreensões pertinentes e comuns, os envolvidos irão perceber as concepções manifestas no PPP, ato que conduza uma construção coletiva e democrática do mesmo. Assim, a elaboração e o teor do documento não se resumirão a apenas um compilado de impressões da equipe gestora, feita por obrigação de atender às disposições legais vigentes, mas pode vir a retratar a convicção epistemológica destes.

Já no referente às limitações do estudo, pode-se destacar que os resultados poderiam ter sido outros casos os sujeitos fossem outros estudantes (outra turma ou mesma todos os estudantes da UE) ou demais professores da Instituição. Ou ainda se fosse em outro espaço temporal, uma vez que as concepções vão se modificando ao longo da formação.

\section{REFERÊNCIAS}

ALVES -MAZZOTTI, A. J. O método nas ciências sociais. In: ALVES -MAZZOTTI, A. J.; GEWANDSZNAJDER, F. O método nas ciências naturais e sociais: pesquisa quantitativa e qualitativa. São Paulo: Pioneira Thomson Learning, 2002. p. 109-187. 
ARANHA, M. L. A. Filosofia da educação. 2 ed. São Paulo: Moderna, 1996.

BOGDAN, R. C.; BIKLEN, S. K. Investigação qualitativa em educação: uma introdução à teoria e aos métodos. Lisboa: Porto Editora, 1994.

BUENO, A. M. de O.; PEREIRA, E. K. R. O. Educação, escola e didática: uma análise dos conceitos das alunas do curso de pedagogia do terceiro ano - UEL. In: II JORNADA DE DIDÁTICA E I SEMINÁRIO DE PESQUISA DO CEMAD, 2013, Londrina. Anais [...]. Londrina: UEL, 2013.

CARVALHO, A. M. P. Os estágios nos Cursos de Licenciaturas. São Paulo: Cengage Learning, 2012.

CHUEIRI, M.S.F. Concepções sobre avaliação escolar. Estudos em Avaliação Educacional, v. 19, n. 39, p. 49-64, jan/abr., 2008.

COUTINHO, C.; LISBOA, E. Sociedade da informação, do conhecimento e da aprendizagem: desafios para a educação no século XXI. Revista de Educação, Lisboa, v. 18, n. 1, p. $5-22,2011$.

DENZIN, N. The research act: a theoretical introduction to sociological methods. 2. ed. New York: Mc Graw-Hill, 1978.

DENZIN, N. K.; LINCOLN, Y. S. The discipline and practice of qualitative research, In: DENZIN, N. K.; LINCOLN, Y. S. Handbook of Qualitative Research. Thousand Oaks: Sage, 2000. p. 1-36.

EEBRM. Projeto Político Pedagógico. Ituporanga: EEBRM, 2018.

FREIRE, M. Observação, Registro, Reflexão: Instrumento Metodológico. Série Seminários. São Paulo: Espaço Pedagógico, 1992.

FLICK, U. Introdução à pesquisa qualitativa. Trad. Joice Elias Costa. 3. ed. Porto Alegre: Artmed, 2009.

HOFFMANN, J. Avaliar para promover: as setas do caminho. Porto Alegre: Mediação, 2009.

KRIPKA, R. M. L.; SCHELLER, M.; BONOTTO, D. L. Pesquisa documental na pesquisa qualitativa: conceitos e caracterização. Revista de Investigações UNAD, v. 14, n. 2, p. 55-73, jul./dec., 2015.

LUCKESI, C. Avaliação da aprendizagem na escola e a questão das representações sociais. Eccos Revista científica, v. 4, n. 2, p. 79-88, 2002.

MICHAELIS. Dicionário brasileiro de Língua Portuguesa. São Paulo: Melhoramentos, 2019. Disponível em: https://michaelis.uol.com.br/modernoportugues/. Acesso em: 26 mar. 2019. 
PIMENTA, S. G.; LIMA, M. S. L. Estágio e docência. 7. ed. São Paulo: Cortez, 2012.

RODRIGUES, A. T. Sociologia da Educação. 6. ed. Rio de Janeiro: Lamparina, 2007.

SANTA CATARINA. Proposta Curricular de Santa Catarina: Educação Infantil, Ensino Fundamental e Médio: Formação docente para educação infantil e séries iniciais. Florianópolis: COGEN/SEED, 1998.

SAVIANI, D. Pedagogia histórico-crítica: primeiras aproximações. São Paulo: Autores Associados, 1984.

Escola e Democracia. 17. ed. São Paulo: Autores Associados, 1987.

O trabalho como princípio educativo frente às novas tecnologias. In: FERRETTI, C. J. et al. Novas tecnologias, trabalho e educação: um debate multidisciplinar. 2 ed. Petrópolis, RJ: Vozes, 1994. p.151-168.

Trabalho e educação: fundamentos ontológicos e históricos. Rev. Bras. Educ. , Rio de Janeiro, v. 12, n. 34, p. 152-165, abril de 2007. Disponível em:

$<$ http://www.scielo.br/scielo.php?script=sci_arttext\&pid=S1413-

24782007000100012\&lng=en\&nrm=iso >. Acesso em 03 nov. 2019. http://dx.doi.org/10.1590/S1413-24782007000100012.

VEIGA, I. P. A. Projeto político-pedagógico da escola: uma construção coletiva. In: VEIGA, I. P. A. (org.). Projeto político-pedagógico da escola: uma construção possível. Campinas (SP): Papirus, 2004. p.11-35.

VIGOTSKY, L. S. Pensamento e linguagem. 1 ed. São Paulo: Martins Fontes. 1987.

ZANELLI, J. C. Pesquisa qualitativa em estudos da gestão de pessoas. Estudos da Psicologia, n. 7, p. 79-88, 2002. 